\title{
Strengthening digital ecosystem for SMEs through readiness to change and agile leadership
}

\author{
Hasan Abdul Rozak ${ }^{1 *}$, Ardian Adhiatma ${ }^{2}$, Ika Rosyada Fitriati ${ }^{3}$ \\ 1,3Faculty of Economics and Business, Universitas Stikubank, Semarang, Indonesia \\ ${ }^{2}$ Faculty of Economics, Universitas Islam Sultan Agung, Semarang, Indonesia \\ *Corresponding author: hasanarozak@edu.unisbank.ac.id
}

Article Info
Article history:
Received : 4 November 2020
Accepted : 15 February 2021
Published : 1 July 2021

JEL Classification Code: M12, L23, L26

\author{
Author's email: \\ ardian@unissua.ac.id \\ ikarosyada@edu.unisbank.ac.id
}

DOI: $10.20885 /$ jsb.vol25.iss2.art6

\begin{abstract}
Purpose: This study aims to describe and analyze the relationship between readiness to change and agile leadership on the dynamic capabilities of SMEs. Furthermore, this study also examines the effect of dynamic capabilities in strengthening the digital ecosystem of SMEs.
\end{abstract}

Design/methodology/approach: The data used in the study are collected from 250 SMEs through structured questionnaires. This study analyzes three hypotheses using structural equation modeling.

Findings: The results of the study show that readiness to change and agile leadership can improve the dynamic capabilities of SMEs. The improved dynamic capabilities of SMEs are proven to be able to strengthen the digital ecosystem in SMEs. The results of this study are expected to contribute to SMEs in strengthening the growth of the digital economy in Indonesia.

Research limitations/implications: This research has several limitation aspects, the research design is cross-sectional, and the research design cannot ensure that the causal relationship is specified in the hypothesis; in fact, the results tend to be consistent with theoretical reasoning. This study analyzes dynamic capabilities, a more specific approach may be needed to be able to fully utilize each process for the realization of a digital ecosystem. Another limitation, this study only examines the direct effect between a penchant for change and agile leadership on the capabilities of SMEs. Then test the direct influence between dynamic capabilities on the realization of a digital ecosystem.

Practical Implications: The implication of the results of this research for management is as a literature on efforts to strengthen the digital ecosystem for SMEs through dynamic capabilities formed fro readiness to change and agile leadership. SME entrepreneurs must realize that change is a necessity along with the development of society and technology so that readiness to change becomes veri important. Besides, SME entrepreneurs are also required to have an agile leadership spirit so that they can guide and influence their team in achieving targets and solving problems properly.

Originality/value: This study focuses on change readiness and agile leadership in relation to the dynamic capabilities of SMEs that can ultimately shape digital ecosystems. the results of this study provide additional empirical evidence for areas of research where there are few studies exist.

Keywords: readiness to change, agile leadership, dynamic capabilities, digital ecosystem, SMEs 


\section{Introduction}

The digital era presents the biggest challenge for SMEs regarding how to increase the accessibility of SMEs to go-digital and improve the capabilities of SMEs. It is expected to produce products that are able to compete with foreign products in Indonesia e-commerce. In this digital era, all business sectors, especially SMEs, are required to adapt to changes in order to survive and have a sustainable competitive advantage. Digitalization in the economic sector has the potential for SMEs to market their products easier, not only in the domestic market but also in the international market or at least crossing the ASEAN regional or cross-border markets. Digitalization in SMEs is expected to result SMEs with a well-integrated digital business ecosystem so that they can continue to compete in the business world. Digitalization allows SMEs to have access to ready-to-use information technology applications which can support business functions, such as marketing (e.g. platforms for e-commerce, including social media applications); finance and accounting (e.g. payments via mobile apps) and human resources (e.g. collaborative tools, such as video conference for coordination).

According to Matopoulos et al. (2012), digital ecosystem is an evolutionary, self-governing system that contributes to sustainable local and regional development through well-defined, integrated and widespread software platforms for organizations (Kutsikos et al., 2014) which is an organization's strategic plan (Kraus et al., 2019). Dynamic capabilities are also considered as a suitable approach for studying the effects of information system or specific information technology capabilities in organizations (Rialti et al., 2019). Dynamic capability is expected to make SMEs maintain their sustainability in implementing business digitalization in the current era. In addition, it can be achieved by knowing the readiness to change in all SME stakeholders, especially owners. It is because, in today's digital era, apart from ability, it is also important to always be ready to respond to business transformation.

Learning to deal with organizational change and implement change programs effectively can be facilitated through investigating an organization's readiness to change (Vakola, 2014). The concept of readiness is interesting because the employees' reactions to change, play an important role in any organizational change (Oreg et al., 2011). In today's competitive world, greater emphasis is placed on issues such as how quickly and flexibly an organization can react to constant changes in its surrounding environment. These problems are based on an important paradigm which is known as agility (Perker et al., 2015). Agility is considered to be a critical basis for today's modern organizations and necessary for their survival (Sanatigar et al., 2017). The more rapid changes in market conditions and organizational flexibility show that organizations need self-organized teams and agile leadership (Dikert et al., 2016). An agile leader is able to overcome ignorance in detail, and able to solve complex problems quickly through the right steps (McPherson, 2016).

SMEs as a dynamic form of business cannot be separated from the change and human resources, especially the leadership of business actors. This research aims to examine the importance of capabilities for SMEs, by determining the effects of readiness to change and agile leadership. Furthermore, it will also examine the impact of dynamic capabilities on the realization of SMEs digital ecosystem. Research on strengthening the digital ecosystem for SMEs is important considering that SMEs are an industrial sector that can absorb more workers than large businesses. The contribution of SMEs to the formation or growth of gross domestic product (GDP) is also greater than the contribution of large businesses. For this reason, it is necessary to conduct research that can support the realization of the digital SME ecosystem so that SMEs are able to adapt intelligently to win the competition in the era of industrial revolution 4.0 and preoare for the era of society 5.0. This research is not only important for the industry but also very important and beneficial for the development of management science, especially human resource management and business development through strengthening digital ecosystems. The results of this research are expected to add literature on the effect of readiness to change and agile leadership on dynamic capabilities which ultimately have an impact on strengthening the digital ecosystem for SMEs. 


\section{Literature Review}

\section{Readiness to Change on Dynamic Capabilities}

Bouckenooghe \& Devos (2008) defined "readiness" as the individual's beliefs, attitudes, and intentions regarding the extent to which change is needed and the organizational capacity to change successfully. Therefore, a responsible leadership for the proposed change is instructed to arrange a change message that addresses the five sentiments of readiness; diversity, efficacy, appropriateness, ultimate support, and personal valence (Hemme et al., 2018). Furthermore, Hemme et al. (2018) stated that organizations in implementing and managing change must be prepared if they do not want all their efforts to fail. The readiness of individuals to change is a critical success factor because organizations only change and act through their members. Indeed, the most collective activities that occur in organizations are the result of combining the activities of individual organizational members (Vakola, 2014). As a concept in organizational level, readiness to change refers to the joint commitment of organizational members in implementing change. It is also a shared belief in their collective ability to change (Budhiraja, 2019). Thus, readiness to change is an individual's belief, attitude, and intention in implementing and managing change which refers to the joint commitment of organizational members. It is a determining factor for success based on shared belief in the collective ability to adapt to change.

Dimensions for measuring readiness to change in their effect on dynamic capabilities include leadership, organizational culture, communication, training, measurement, and reward systems (Al-Balushi et al., 2014). Moreover, Antony (2014) identified five main readiness factors, they are: (1) leadership and vision; (2) commitment and management resources; (3) connecting lean six sigma with company strategy; (4) customer focus; and (5) choosing the right person. Uluskan et al. (2018) measured readiness to change by using dimensions: Commitment of managers to change due to new implementations; Commitment of employees to change due to new implementations; Communication of information; Clearly defined (financial) benefits/outcome of quality methods; Clear definition of customer requirements; and Knowledge and training in quality methods. Meanwhile, Vakola (2014) measured readiness to change by using dimensions: Core selfevaluations, Perceived impact of change, Trust in management, Communication climate, and Job satisfaction. Budhiraja (2019) also stated the determinants of readiness to change that consist of: top management involvement, organizational infrastructure, employees attribute, employees' attitude, active involvement of employees, development of skill set, augmented social interaction, and systematize the change.

Based on research conducted by Chênevert et al., (2019), readiness to change is related to turnover intention with higher absenteeism levels and actual turnover. It means, the more unprepared an individual to respond a change, the higher the level of absenteeism and turnover. Meanwhile, Hemme et al. (2018) stated that readiness to change affects organizational engagement and dynamic capabilities (Uluskan et al., 2018; Vakola, 2014). Thus, the hypothesis can be formulated as follows:

H1: The higher the level of readiness to change, the higher the dynamic capabilities of SMEs.

\section{Agile Leadership on Dynamic Capabilities}

Agile leaders can guide teams and continuously influence team behavior by defining, disseminating and maintaining the organization's vision (Perker et al., 2015). The agile entrepreneur is obsessed with providing value to customers. In an agile organization, "customer focus" means that everyone in the organization has a clear view about the key customers and can see how their work adds value to customers (Denning, 2018). Marques (2018) stated that the entire performance environment, whatever it is, is fast-paced today and agility is the key to survive in the business game. Agile leadership means being agile in influencing others and making changes (Sanatigar et al., 2017). Agility is considered to be one of the key skills for today's managers. An agile manager who has multiple skills with flexibility and speed can facilitate the achievement of greater organizational success and ready to face the the current challenges (Buhler, 2010). In conclusion, agile leadership is an agile leadership that can guide the team and continuously influence the team's behavior to 
always provide value to customers. It can be achived by having many skills with flexibility and speed that can facilitate the success of a bigger organization in order to always be ready in facing the challenges of the business world. Agile leaders are able to establish guiding principles, develop strategies, and build mechanisms that will lead to a smooth transition to organizational agility (Attar \& Abdul-Kareem, 2020).

Perker et al. (2015) stated that the dimensions of agile leadership are sense of urgency and direction, hard work upfront - sets expectations and norms, shares responsibility and mutual accountability, effective in recognizing problems and making decisions, commitment and trust amongst members, balances individual and group needs, cohesive without stifling individuality, confronts differences and deals with conflicts, deals with minority opinions effectively, and effective communication methods. Agile leadership guidelines consist of: intrinsic ability to deal with change; organizational views, adaptive system; recognition in the limitations of external controls; a humanistic approach to solve problems; the collective ability of autonomous teams as a basic problem-solving mechanism; limiting advance planning to a minimum based on the assumption of uncertainty; adaptability; react according to the results of self-managed teams; and manage the results (Gardner et al., 2005). The other dimensions of agile leadership are customer-first mindset, focus on the road map for the future, continuous creation of new businesses, multiple paths to yes, willingness to take risks and acquire new institutional skills, and turning institutional skills into new businesses (Denning, 2018). In addition, Sanatigar et al. (2017) mentioned the dimensions to measure agile leadership are collaboration and nurturance, accepting diversity, competency, innovation and creativity, transparency and trust, flexible structure, appropriate and smooth, regulations and directives, new methods and processes for performing work, robust - high speed and updated hardware and infrastructures, appropriate and timely software and programs.

Sanatigar et al. (2017) suggested that this research provides a new method for the analysis, measurement and development of organizational agility constructs in public service organizations performance in Iran. Meanwhile, another study stated that agile leadership affects the dynamic capabilities of an organization (Denning, 2018; Marques, 2018; McKenzie \& Aitken, 2012; McPherson, 2016; Perker et al., 2015). Hence the hypothesis is as follows:

H2: The higher the level of agile leadership, the higher the dynamic capabilities of SMEs.

\section{Digital Ecosystem}

Sussan \& Acs (2017) argued that Digital ecosystem is a self-regulating, scalable, and sustainable system consisting of heterogeneous and interrelated digital entities. It focuses on interactions among entities to increase the system utility, gain benefits, and promote information exchange. Kraus et al. (2019) explained that digital ecosystem has a kind of self-generative trait which works on a service-oriented logic. It allows users to act as providers at the same time. In other words, digital ecosystem is an idea of service-oriented technology ecosystem to facilitate operations that focus on digital industry and interactions among entities. It aims to increase system utility, gain benefits, and promote information exchange.

According to Kraus et al. (2019), digital ecosystem is measured by using the dimensions of Institutional entrepreneurship, Transaction costs, Digital technology, and Online social capital (Sussan \& Acs., 2017; Wu \& Chen, 2018). Matopoulos et al. (2012) added that digital ecosystem dimensions consist of governance, regulations and industrial policy; human capital, knowledge and practices; service and technical infrastructure; and business and financial conditions.

\section{Dynamic Capabilities and Digital Ecosystem}

Dynamic capabilities are related to the ability of an organization to adapt adequately and in a timely manner to a changing environment. It is realized by reconfiguring internal or external processes and resources with the existing competencies (Yu et al., 2017). Dynamic capability will enable the dissemination of knowledge to everyone in the organization (Rialti et al., 2019) which is necessary for their resource base and capabilities in order to remain competitive, particularly in facing a changing market environment (Schilke et al., 2018). The absence of dynamic capabilities is seen as a threat that can hamper the company's ability to maintain performance levels in a new and 
changing environment (Gnizy et al., 2014). Dynamic capabilities are characterized by persistent long-term patterns of company behavior that facilitate adaptation (Zollo \& Winter, 2002). However, they do not directly affect company performance. In conclusion, dynamic capabilities are the abilities of organizations to adapt adequately and in a timely manner to a changing environment for their resource base and ability in order to remain competitive. This can be achieved by disseminating knowledge to everyone in the organization in a persistent long-term pattern.

Gnizy et al. (2014) suggested that dynamic capabilies can be measured by marketing program adaptation dan local integration. Furthermore, Oliva et al. (2018) measured dynamic capabilities by integration of individuals' expertise in the organization; culture, orientation and leadership; and corporate strategies. The other dimensions are markets, technologies and regulations (Park et al., 2018) sensing, seizing, transforming (Tallott \& Hilliard, 2016) the ability to identify and explore emerging opportunities and new sources of competitive advantages (Bamel \& Bamel, 2018; Schilke et al., 2018) sensing, learning, integrating, and coordinating capability (Hernández-Linares et al., 2021) strong coordination, and competitive response to the rivals (Rehman \& Saeed, 2018).

According to the research by Gnizy et al. (2014), dynamic capabilities affect the success factors of SMEs, one of which is to go digital. Further research by Park et al. (2018) showed that dynamic capabilities as measured by market conditions, technology and regulation that affect company performance in driving digital business (Oliva et al., 2018; Rialti et al., 2019; Tallott \& Hilliard, 2016). Thus, the hypothesis is formulated as follows:

H3: The higher the dynamic capabilities of SMEs, the higher the digital ecosystem.

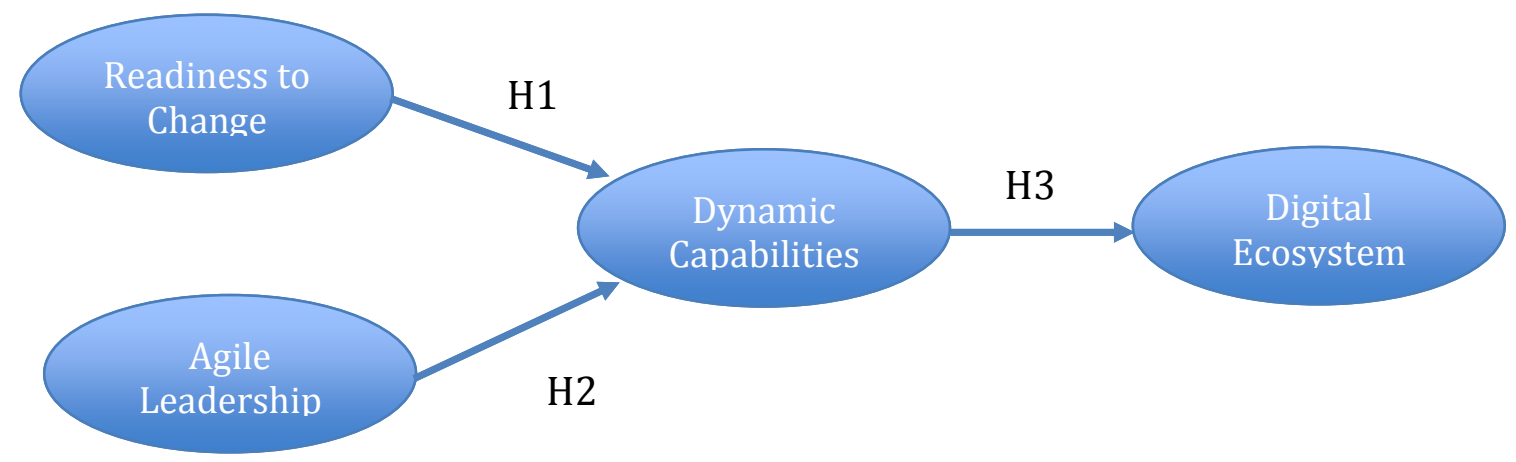

Figure 1. Research Empirical Model

\section{Methods}

This research was categorized as an explanatory research to analyze the digital ecosystem enhancement of SMEs. The samples were determined by using non-random sampling with purposive sampling method. This research involved $250 \mathrm{SME}$ owners/leaders/managers in Central Java as respondents. The criteria for respondents in this research were SMEs that had at least 10 employees, and used Information Technology in their supply chain activities, for example in the procurement of raw materials, production processes, and product delivery to customers. The data were collected through questionnaires. The list of questions was arranged in stages based on a Likert scale of 1 - 5 measurement.

\section{Measurement and Analysis}

This research used analytical methods in managing data. Meanwhile, in testing the hypotheses, the researchers used Structural Equational Modeling (SEM) which was operated through the Partial Least Squares (PLS) program. SEM was used as the analysis technique in order to thoroughly explain the relationship among variables in the research.

In this research, to measure the level of digital ecosystem realization in SMEs, it involved the dimensions of digital technology, institutional entrepreneurship, and online social capital (Wu \& Chen, 2018; Kraus et al., 2019; Matopoulos et al., 2012; Sussan \& Acs., 2017). Meanwhile, to 
find out dynamic capabilities, this research used the dimensions of sensing capability, adaptive capability, learning capability, networking capability, innovative capability, integrating capability and coordinating capability (Gnizy et al., 2014; Hernández-Linares et al., 2021; Oliva et al., 2018; Park et al., 2018; Rehman \& Saeed, 2018; Tallott \& Hilliard, 2016). The dimensions to measure readiness to change include organizational learning, organizational infrastructure, commitment and management resources, and communication climate (Al-Balushi et al., 2014; Antony, 2014; Budhiraja, 2019; Vakola, 2014). Furthermore, the dimensions for measuring agile leadership include: shares responsibility, effective recognition problems and making decisions, adaptive systems, and flexible structure (Denning, 2018; Perker et al., 2015; Sanatigar et al., 2017).

The results of instrument quality measurement test showed that the Cronbach's value on readiness to change was 0.875 , agile leadership was 0.870 , dynamic capability was 0.881 and digital ecosystem was 0.699 . It can be concluded that all variables were reliable, because the Cronbach's value was above 0.7 .

\section{Result and Discussion}

The test of proposed conceptual model included testing measurement models and structural models. Meanwhile, to test the hypotheses, this research used WrapPLS as an analysis tool.

\section{Measurement Model (Outer Model)}

The test results showed that the indicators in this research were valid and reliable because they had met the convergent validity as presented in Table 1 . The loading factor value must be 0.7 but the value 0.4-0.7 is still acceptable. In addition, it is also seen from the value of Average Variance Extracted (AVE) that must be greater than 0.5 (Ghozali \& Latan, 2015). The discriminant validity test also showed that the model fulfills the discriminant validity. The test results showed that the square root value of AVE was greater than the correlation value among constructs as shown in Table 2.

Table 1. Combined Loadings and Cross -Loading Values

\begin{tabular}{lcccc}
\hline \multicolumn{1}{c}{ Variable } & $\begin{array}{c}\text { Loading } \\
\text { Value }\end{array}$ & AVE & p-value & Information \\
\hline Readiness to change & & 0.730 & $<0.001$ & Valid \\
RtC1 & 0.865 & & $<0.001$ & Valid \\
RtC2 & 0.814 & & $<0.001$ & Valid \\
RtC3 & 0.927 & & $<0.001$ & Valid \\
RtC4 & 0.805 & & & \\
Agile Leadership & & 0.721 & $<0.001$ & Valid \\
AL1 & 0.777 & & $<0.001$ & Valid \\
AL2 & 0.899 & & $<0.001$ & Valid \\
AL3 & 0.882 & & $<0.001$ & Valid \\
AL4 & 0.833 & & & \\
Dynamic Capabilities & & 0.585 & $<0.001$ & Valid \\
DC1 & 0.816 & & $<0.001$ & Valid \\
DC2 & 0.835 & & $<0.001$ & Valid \\
DC3 & 0.751 & & $<0.001$ & Valid \\
DC4 & 0.752 & & $<0.001$ & Valid \\
DC5 & 0.763 & & $<0.001$ & Valid \\
DC6 & 0.729 & & Valid \\
DC7 & 0.697 & 0.757 & $<0.001$ & Valid \\
Digital Ecosystem & & & $<0.001$ & Valid \\
DE1 & 0.804 & & & Valid \\
DE2 & 0.760 & & \\
DE3 & 0.806 & & & \\
\hline Source: Wapt & & & \\
\hline
\end{tabular}

Source: WrapPLS Output 
Table 2. The Correlation among Variables with Square Roots of AVEs

\begin{tabular}{ccccc}
\hline & $\mathrm{KuB}$ & $\mathrm{KL}$ & $\mathrm{KD}$ & $\mathrm{ED}$ \\
\hline $\mathrm{RtC}$ & $\mathbf{0 . 8 5 4}$ & 0.647 & 0.735 & 0.577 \\
$\mathrm{AL}$ & 0.647 & $\mathbf{0 . 8 4 9}$ & 0.639 & 0.422 \\
$\mathrm{DC}$ & 0.735 & 0.639 & $\mathbf{0 . 7 6 5}$ & 0.598 \\
$\mathrm{DE}$ & 0.577 & 0.422 & 0.598 & $\mathbf{0 . 7 9 1}$ \\
\hline
\end{tabular}

Source: WrapPLS Output

\section{Structural Model (Inner Model)}

The determinant coefficient was used to measure the ability of exogenous variables in order to explain endogenous variables. The expected $\mathrm{R}$-square value was between 0 and 1 . The $\mathrm{R}$-square results of all endogenous variables indicated the predictive ability of the model. The R-square values of $0.75,0.50$ and 0.25 showed that the ability of endogenous variables in predicting the model was strong, moderate and weak (Hair et al., 2017).

Table 3. R-Square Result

\begin{tabular}{lcc}
\hline \multicolumn{1}{c}{ Variable } & R-Squared & Adjusted R-Squared \\
\hline Dynamic Capabilities & 0.606 & 0.603 \\
Digital Ecosystem & 0.344 & 0.339 \\
\hline
\end{tabular}

Source: WrapPLS Output

Based on the results of the R-square test in Table 3, it can be concluded that the endogenous variable which were dynamic capabilities and digital ecosystems had moderate abilities of 0.606 and 0.344 in predicting the model. It can be persumed that readiness to change and agile leadership had the ability to predict $60.6 \%$ on dynamic capabilities. Meanwhile, the rest was determined by other variables outside of this research. Furthermore, the exogenous variables which were readiness to change and agile leadership had predictive ability of $34.4 \%$ in the digital ecosystem, whereas the rest were influenced by other variables outside of this research.

Table 4. The Results of Path Coefficient Method WrapPLS

\begin{tabular}{|c|c|c|c|c|}
\hline & Hypothesis & Path Coefficients & P-Value & Conclusion \\
\hline & $\begin{array}{l}\text { The higher the level of readiness to change, the } \\
\text { higher the dynamic capabilities of SMEs. }\end{array}$ & 0.589 & $<0.001$ & Supported \\
\hline H2: & $\begin{array}{l}\text { The higher the level of agile leadership, the higher } \\
\text { the dynamic capabilities of SMEs. }\end{array}$ & 0.529 & $<0.001$ & Supported \\
\hline H3: & $\begin{array}{l}\text { The higher the dynamic capabilities of SMEs, the } \\
\text { higher the digital ecosystem realization. }\end{array}$ & 0.324 & $<0.001$ & Supported \\
\hline
\end{tabular}

Source: WrapPLS Output

The direct effect of the readiness to change of SMEs on the digital ecosystem realization had the coefficient value of 0.589 and $p$-value of $<0.001$ ( $\mathrm{p}$-value $<0.05$ ). The results of the analysis were in accordance with the predictions that had been made, hence the first hypothesis (H1) was supported. These findings were similar with the findings of Uluskan et al., 2018. This showed that the higher the level of readiness to change, the higher the dynamic capabilities of SMEs. The results of this hypothesis test indicated that the higher the level of readiness to change, the higher the dynamic capabilities of SMEs. The dynamic capabilities of SMEs were determined by the level of readiness to change. SMEs' readiness to change provided capabilities such as adaptation, learning, networking, integration, and coordination; thus, dynamic capabilities can be achieved.

The second hypothesis indicated that the effect of agile leadership on dynamic capabilities had a coefficient value of 0.529 and a p-value of $<0.001$ ( $\mathrm{p}$-value $<0.05$ ). The results of the analysis were also in accordance with the predictions that had been made; thus, the second hypothesis $(\mathrm{H} 2)$ 
was supported. This was similar with the research done by Denning (2018) and Marques (2018). According to Sanatigar et al. (2017), SMEs with agile leadership are characterized by the ability to collaborate and nurturance, accept diversity, competence, innovation and directives, discover new methods and processes for performance improvement, robust - high speed and update hardware and infrastructure, appropriate and timely software and programs, proven to affect the dynamic capabilities in SMEs. An improvement in agile leadership ability of SMEs is proven to be able to improve their dynamic capabilities. A capable leader can apply values and experience to a variety of services or areas of a business that seem completely different (McPherson, 2016).

Meanwhile, the effect of dynamic capabilities on the SMEs digital ecosystem realization had coefficient value of 0.324 and a p-value of $<0.001$ ( $p$-value $<0.05$ ). The results of the analysis were in accordance with the predictions that had been made, as the result the third hypothesis $(\mathrm{H} 3)$ was supported. Park et al. (2018) also found that dynamic capabilities consisting of market conditions, technology and regulation affect company performance in driving the digital business ecosystem (Rialti et al., 2019; Fachrunnisa, 2016; Fachrunnisa \& Hussain, 2013). In the end, this research succeeded in proving that a high level of dynamic capabilities made a significant contribution in realizing a digital ecosystem for SMEs. Meanwhile, the dynamic capabilities of SMEs will be achieved if the leader has agility and readiness to change.

\section{Conclusion}

The first objective of this research was to analyze the effect of readiness to change on dynamic capability level of SMEs. This finding was supported by previous research of Uluskan et al. (2018), Hemme et al. (2018), and Vakola, 2014 who stated that readiness to change has an effect on organizational engagement and dynamic capabilities

The second objective had examined the effect of agile leadership on the achievement of the dynamic capabilities in SMEs. The results of this research verified that readiness to change and agile leadership in SMEs were requirements for the growth of dynamic capabilities in order to create a digital ecosystem for SMEs. The result ensured that agile leadership was the antecedent of dynamic capabilities in order to realize a digital ecosystem for SMEs.

The main point of this finding is that SMEs must have readiness to change and agile leadership, so that they are able to improve the dynamic capabilities. In the end, the high level of capability in SMEs will affect the realization of a digital ecosystem. The implication of the results of this research for management is as a literature on efforts to strengthen the digital ecosystem for SMEs through dynamic capabilities formed for readiness to change and agile leadership. SME entrepreneurs must realize that change is a necessity along with the development of society and technology so that readiness to change becomes very important. Besides, SME entrepreneurs are also required to have an agile leadership spirit so that they can guide and influence their team in achieving targets and solving problems properly.

However, this research has the following limitations aspect. First, the research design was cross-sectional and the research design could not confirm that a causal relationship was established in the hypothesis. In fact, the results tended to be consistent with theoretical reasoning. Future research can provide an alternative solution to this problem by applying a longitudinal design. Second, this research analyzed dynamic capabilities such as sensing capability, adaptive capability, learning capability, networking capability, innovative capability, integrating capability, and coordinating capability. However, a more specific approach might be needed in order to take full advantage of each process for the realization of digital ecosystem. As the result, when SMEs needed creativity and experiment to deal with scenarios of radical change, agile leadership may be the most appropriate. Whereas in a more stable situation, another leadership style might be more appropriate because all organizations, even SMEs, basically pursued stability. In this case, future studies may try to describe other types of leadership with different environmental and time settings. This research only examined the direct effect between readiness to change and agile leadership on the capabilities of SMEs. Afterwards, it tested the direct effect between dynamic capabilities and the realization of digital ecosystem. Therefore, further research is necessary to test the level of dynamic 
capabilities in SMEs to mediate readiness to change and agile leadership towards the digital ecosystem realization.

\section{References}

Al-Balushi, S., Sohal, A. S., Singh, P. J., Al Hajri, A., Al Farsi, Y. M., \& Al Abri, R. (2014). Readiness factors for lean implementation in healthcare settings--a literature review. Journal of Health Organization and Management, 28(2), 135-153.

Antony, J. (2014). Readiness factors for the Lean Six Sigma journey in the higher education sector. International Journal of Productivity and Performance Management, 63(2), 257-264.

Attar, M., \& Abdul-Kareem, A. (2020). The Role of Agile Leadership in Organisational Agility. Agile Business Leadership Methods for Industry 4.0, 171-191.

Bamel, U. K., \& Bamel, N. (2018). Organizational resources, KM process capability and strategic flexibility: a dynamic resource-capability perspective. Journal of Knowledge Management, 22(7), 1555-1572.

Bouckenooghe, D., \& Devos, G. (2008, August). Psychological Change Climate As A Crucial Catalyst of Readiness For Change. In Academy of Management Proceedings (Vol. 2008, No. 1, pp. 1-6). Briarcliff Manor, NY 10510: Academy of Management.

Budhiraja, S. (2019). Organizational readiness for change: an inherent concern for Indian small and medium enterprises (SMEs). Development and Learning in Organizations, 33(2), 4-7.

Buhler, P. (2010). The Agile Manager. Supervision, 71(12), 18-20.

Chênevert, D., Kilroy, S., \& Bosak, J. (2019). The role of change readiness and colleague support in the role stressors and withdrawal behaviors relationship among health care employees. Journal of Organizational Change Management, 33(2), 208-223.

Denning, S. (2018). The role of the C-suite in agile transformation: The case of amazon. Strategy and Leadership, 46(6), 14-21.

Dikert, K., Paasivaara, M., \& Lassenius, C. (2016). Challenges and success factors for large-scale agile transformations: A systematic literature review. Journal of Systems and Software, 119, 87108.

Fachrunnisa, O. (2016). Towards sustainability of virtual business community through trustworthy behaviour-based mechanism. International Journal of Web Based Communities, 12(3), 296-322.

Fachrunnisa, O., \& Hussain, F. K. (2013). A methodology for maintaining trust in industrial digital ecosystems. IEEE Transactions on Industrial Electronics, 60(3), 1042-1058.

Gardner, W., Avolio, B., \& Walumbwa, F. (2005). Authentic Leadership Theory \& Practice. Bridgewater, NJ: Elsevier Science.

Ghozali, I., \& Latan, H. (2015). Partial Least Squares, konsep, teknik dan aplikasi menggunakan program Smartpls 3.0 untuk penelitian empiris. Semarang: Badan Penerbit Universitas Diponegoro.

Gnizy, I., Baker, W. E., \& Grinstein, A. (2014). Proactive learning culture: A dynamic capability and key success factor for SMEs entering foreign markets. International Marketing Review, 31(5), 477-505.

Hair, J. F., Hult, G. T. M., Ringle, C. M., \& Sarstedt, M. (2017). A Primer on Partial Least Squares Structural Equation Modeling (PLS-SEM) (Second Edi). Los Angeles: SAGE Publicstion.

Hemme, F., Bowers, M. T., \& Todd, J. S. (2018). Change readiness as fluid trajectories: a longitudinal multiple-case study. Journal of Organizational Change Management, 31(5), 11531175.

Hernández-Linares, R., Kellermanns, F. W., \& López-Fernández, M. C. (2021). Dynamic 
capabilities and SME performance: The moderating effect of market orientation. Journal of Small Business Management, 59(1), 162-195.

Kraus, S., Palmer, C., Kailer, N., Kallinger, F. L., \& Spitzer, J. (2019). Digital entrepreneurship: A research agenda on new business models for the twenty-first century. International Journal of Entrepreneurial Behaviour and Research, 25(2), 353-375.

Kutsikos, K., Konstantopoulos, N., Sakas, D., \& Verginadis, Y. (2014). Developing and managing digital service ecosystems: A service science viewpoint. Journal of Systems and Information Technology, 16(3), 233-248.

Marques, J. (2018). What's new in leadership? Human Resource Management International Digest, 26(4), $15-18$.

Matopoulos, A., Herdon, M., Várallyai, L., \& Péntek, Á. (2012). Digital business ecosystem prototyping for SMEs. Journal of Systems and Information Technology, 14(4), 286-301.

McKenzie, J., \& Aitken, P. (2012). Learning to lead the knowledgeable organization: developing leadership agility. Strategic HR Review, 11(6), 329-334.

McPherson, B. (2016). Agile, adaptive leaders. Human Resource Management International Digest, 24(2), $1-3$.

Oliva, F. L., Couto, M. H. G., Santos, R. F., \& Bresciani, S. (2018). The integration between knowledge management and dynamic capabilities in agile organizations. Management Decision, 57(8), 1960-1979.

Oreg, S., Vakola, M., \& Armenakis, A. (2011). Change recipients' reactions to organizational change: A 60-year review of quantitative studies. The Journal of Applied Behavioral Science, 47(4), 462-524.

Park, H. Y., Misra, K., Reddy, S., Jaber, K., Park, H. Y., Misra, K., Jaber, K. (2018). Family firms ’ innovation drivers and performance $\square$ : a dynamic capabilities approach. Journal of Family Business Management, 9(1), 4-23.

Perker, D. W., Holesgrove, M., \& Pathak, R. (2015). Improving productivity with self-organised teams and agile leadership. International Journal of Productivity and Performance Management, 64(1), 112-128.

Rehman, K. U., \& Saeed, Z. (2018). Impact of Dynamic Capabilities on Firm Performance: Moderating Role of Organizational Competencies. Sukkur IBA Journal of Management and Business, 2(2), 20.

Rialti, R., Marzi, G., Ciappei, C., \& Busso, D. (2019). Big data and dynamic capabilities $\square$ : a bibliometric analysis and systematic literature review capabilities. Management Decision, 24(5), 1091-1109.

Sanatigar, H., Peikani, M. H., \& Gholamzadeh, D. (2017). Identifying organizational agility and leadership dimensions using Delphi technique and factor analysis: an investigating among public sector pension funds (PSPFs) in Iran. International Journal of Public Leadership, 13(4), 276-294.

Schilke, O., Hu, S., \& Helfat, C. E. (2018). Quo vadis, dynamic capabilities? A content-analytic review of the current state of knowledge and recommendations for future research. Academy of Management Annals, 12(1), 390-439.

Sussan, F., \& Acs, Z. J. (2017). The digital entrepreneurial ecosystem. Small Business Economic, 49, $55-73$.

Tallott, M., \& Hilliard, R. (2016). Developing dynamic capabilities for learning and internationalization: A case study of diversification in an SME. Baltic Journal of Management, 11(3), 328-347. 
Uluskan, M., McCreery, J. K., \& Rothenberg, L. (2018). Impact of quality management practices on change readiness due to new quality implementations. International Journal of Lean Six Sigma, 9(3), 351-373.

Vakola, M. (2014). What's in there for me $\square$ ? Individual readiness to change and the perceived impact of organizational change. Leadership and Organizational Journal, 35(3), 195-209.

Wu, C., \& Chen, T. (2018). International Journal of Hospitality Management Collective psychological capital: Linking shared leadership, organizational commitment, and creativity. International Journal of Hospitality Management, 74(February), 75-84.

Yu, X., Meng, X., \& Chen, Y. (2017). Technological Forecasting \& Social Change Work-family con $\mathrm{fl}$ ict, organizational ambidexterity and new venture legitimacy in emerging economies. Technological Forecasting \& Social Change, (October), 1-12.

Zollo, M., \& Winter, S. (2002). Deliberate learning and the evolution of dynamic capabilities. Organization Science, 13(3), 339-351. 